\title{
Continued growth, continual progress, and continuous publications
}

\author{
Royston Goodacre ${ }^{1}$
}

Published online: 15 December 2015

(C) Springer Science+Business Media New York 2015

Welcome to the twelfth volume of the new look Metabolomics.

2016 is an exciting time for metabolomics in terms of the continued growth and continual progress being made within all areas of this vibrant research field. Approximately 10,000 articles have been published per annum in the last 3 years, ${ }^{1}$ and this is likely to increase further. Thus with the increased urgency for authors to have the finalised version of their studies and reviews published early, this has led to some changes in Metabolomics.

The Editorial Advisory Board and I recently discussed the need for the journal to move to a Continuous Article Publication mode to speed up the publication process. This was agreed and is now in place. So you may be asking yourself: What does this mean? What happens to my paper when it has been accepted? How long do I have to wait to see the final version of the paper published? And when do I get my $\mathrm{DOI}^{2}$ ?

What this means is that the finalised version of any paper will now be published electronically with an article number, rather than having page numbers. As an author this will have a few consequences on the speed of the postacceptance process:

- The article will be published in its final form much earlier: this is estimated to be circa 1-2 months, compared to the current 6-8 months.

Royston Goodacre

Roy.Goodacre@manchester.ac.uk

1 School of Chemistry and Manchester Institute of Biotechnology, University of Manchester, 131 Princess Street, Manchester M1 7DN, UK
- The galleys will be produced shortly after an article is accepted and at this stage the article will be assigned its DOI.

- From 2016 onwards there will be 12 virtual issues per annum. These coincide with the indexing of the journal with various bibliographic databases.

This new publication modus operandi means that there will no longer be a formally printed version of the article. Thus there are no restrictions on the use of colour in figures and tables. Although authors may like to consider the fact that some readers will still print their paper off_-often in monochrome-in order to read the article-perhaps in front of the fire at home, maybe wearing slippers and displaying other dinosaurian behaviours!

Potential authors should note that there is still an expectation that the average length of a primary paper remains at seven printed pages, and these papers would typically contain a maximum of six [Figures + Tables]. The journal is on record stating that shorter articles are more likely to well written, as every word is thought to be more precious, and as a consequence papers are often more carefully constructed and therefore likely to be more interesting, as well as more impactful (Goodacre 2013).

The journal shall continue to feature the most significant work on the front cover of each of the 12 virtual issues. Authors are encouraged to consider potential artwork for the front cover of these issues. If an author has any thoughts on suitable artwork that captures the nature of the work, then they should email the editor processing the article after the manuscript is accepted for publication. Work featured on the front cover provides an excellent

\footnotetext{
${ }^{1}$ Source: Thomson Reuters Web of Science using the search term 'METABOLOM* OR METABONOM*' in the TOPIC field.

${ }^{2}$ You may need this for grant applications etc.
} 
opportunity for the study performed to have an increased profile and thereby reach a wider audience.

I will close by wishing you a peaceful and prosperous 2016 and shall take this opportunity to remind all readers that Metabolomics regularly uses social media and brief updates on the journal, key research and findings published in Metabolomics, as well as other journals, can be found on twitter: @metabolomics.

\section{Reference}

Goodacre, R. (2013). The devil is in the detail. Metabolomics, 9, 1-2. 